\title{
Treatment of human astrocytoma U87 cells with silicon dioxide nanoparticles lowers their survival and alters their expression of mitochondrial and cell signaling proteins
}

\author{
This article was published in the following Dove Press journal: \\ International Journal of Nanomedicine \\ 18 September 2010 \\ Number of times this article has been viewed
}

James CK Lai'

Gayathri Ananthakrishnan ${ }^{1,2}$

Sirisha Jandhyam'

Vikas V Dukhande'

Alok Bhushan'

Mugdha Gokhale'

Christopher K Daniels'

Solomon W Leung ${ }^{3}$

'Department of Biomedical and Pharmaceutical Sciences, College of Pharmacy and Biomedical Research Institute, ${ }^{2}$ Department of Health and Nutrition Sciences, Kasiska College of Health Professions, ${ }^{3}$ Department of Civil and Environmental Engineering, College of Engineering and Biomedical Research Institute, Idaho State University, Pocatello, ID, USA
Correspondence: Solomon W Leung Department of Civil and Environmental Engineering, College of Engineering and Biomedical Research Institute, Idaho State University, Pocatello, ID, USA

Email leunsolo@isu.edu
Abstract: Recent evidence suggests silicon dioxide micro- and nanoparticles induce cytotoxic effects on lung cells. Thus, there is an increasing concern regarding their potential health hazard. Nevertheless, the putative toxicity of nanoparticles in mammalian cells has not yet been systematically investigated. We previously noted that several metallic oxide nanoparticles exert differential cytotoxic effects on human neural and nonneural cells. Therefore, we hypothesized that silicon dioxide nanoparticles induce cytotoxicity in U87 cells by lowering their survival by decreasing cell survival signaling and disturbing mitochondrial function. To investigate this hypothesis, we determined the activities of the key mitochondrial enzymes, citrate synthase and malate dehydrogenase, in astrocytoma U87 cells treated with silicon dioxide nanoparticles. In addition, we studied the expression of the mitochondrial DNA-encoded proteins, cytochrome C oxidase II and nicotinamide adenine dinucleotide (NADPH) dehydrogenase subunit 6 , and cell signaling pathway protein extracellular signal-regulated kinase (ERK) and phosphorylated ERK in treated U87 cells. The activated form of ERK controls cell growth, differentiation, and proliferation. In parallel, we determined survival of U87 cells after treating them with various concentrations of silicon dioxide nanoparticles. Our results indicated that treatment with silicon dioxide nanoparticles induced decreases in U87 cell survival in a dose-related manner. The activities of citrate synthase and malate dehydrogenase in treated U87 cells were increased, possibly due to an energetic compensation in surviving cells. However, the expression of mitochondrial DNA-encoded cytochrome $\mathrm{C}$ oxidase subunit II and NADH dehydrogenase subunit 6 and the cell signaling protein ERK and phosphorylated ERK were altered in the treated U87 cells, suggesting that silicon dioxide nanoparticles induced disruption of mitochondrial DNA-encoded protein expression, leading to decreased mitochondrial energy production and decreased cell survival/proliferation signaling. Thus, our results strongly suggest that the cytotoxicity of silicon dioxide nanoparticles in human neural cells implicates altered mitochondrial function and cell survival/proliferation signaling.

Keywords: cytotoxicity, silicon dioxide nanoparticles, mitochondrial enzyme, extracellular signaling regulated kinase, cell signaling, neural cells

\section{Introduction}

According to the Environmental Protection Agency, exposure to nanomaterials can occur during the manufacturing or production process, and also has the potential to pollute the environment, ${ }^{1}$ in this case the occupational environment. A case in point is exposure to silicon dioxide nanoparticles because silicon dioxide, including a range of its particle sizes, is being used in cosmetics, food, ${ }^{2}$ and drug formulations. ${ }^{3}$ 
In general, silicon dioxide is viewed as a nontoxic substance and its industrial applications are numerous. ${ }^{2-4}$ Nevertheless, there have been reports, at least in the last two decades, that silicon dioxide particles are not as harmless as they were previously assumed to be.

When the size of silicon dioxide is above the micrometer scale (ie, $>1 \mu \mathrm{m}$ ), it appears to be benign to human, insects, and microorganisms. However, diatomaceous earth, which contains more than $85 \%$ of amorphous silicon dioxide, is used as insecticide in dust form, ${ }^{4}$ but its toxicity to insects is not well defined. When the size of silicon dioxide is in the micrometer scale and below, several toxic effects have been observed in humans and animals. Most noticeable is the disease of silicosis in humans, ${ }^{5}$ resulting from prolonged exposure to crystalline silica dust, and similar symptoms have also been reported in rats. ${ }^{5}$ Thus far, silicon dioxide toxicity reports have been almost exclusively on particle sizes at the micrometer scale, and mostly concerning pulmonary injuries or lung inflammation. ${ }^{5,6}$ Few studies have been conducted on silicon dioxide at the nanometer scale, , 5 and even fewer studies so far reported have been conducted with human cells.

In macroscopic sizes, silicon dioxide is not known to be cytotoxic. ${ }^{2,3,5,6}$ However, a recent study demonstrated that exposure of amorphous spherical silicon dioxide nanoparticles of different sizes induced decreases in viability of human endothelial cells, an expression of their cytotoxicity which was apparently dependent on their particle size. ${ }^{7}$ Nevertheless, few, if any, studies have examined the putative cytotoxic effects of silicon dioxide nanoparticles on human neural cells.

There was an early study indicating that silica particles (in the micrometer and nanometer ranges) when introduced into the brains of rats and mice induced an inflammatory response in brain astrocytes and macrophages, and the degeneration of some adjacent axons and axon terminals, as elucidated by light and electron microscopy. ${ }^{8}$ Furthermore, silicon and aluminum were found to be co-localized in the central region of senile plaque cores in the cortex of patients with senile dementia of the Alzheimer type, ${ }^{9}$ and the accumulated silicon and aluminum appeared to be localized, at least in part, in lipofuscin granules in the brains of patients who died with Alzheimer's disease. ${ }^{10}$ Consequently, these early studies ${ }^{8-10}$ suggest that silicon dioxide nanoparticles may exert cytotoxic effects on neural cells.

We recently found that exposure to titanium dioxide and two other metallic oxide (namely, $\mathrm{ZnO}$ and $\mathrm{MgO}$ ) nanoparticles induced differential cytotoxicity on human neural cells. ${ }^{11}$ Because of our recent findings ${ }^{11}$ and the increasing evidence that a variety of nanoparticles (including silicon dioxide-containing nanoparticles) can cross the blood-brain barrier, ${ }^{12,13}$ we initiated this study to investigate the putative cytotoxic effect(s) of silicon dioxide nanoparticles on human neural cells. In particular, we focused on investigation of the putative cytotoxic effects of these nanoparticles on mitochondrial function and survival cell signaling in human astrocytoma U87 cells that are astrocyte-like in view of the fact that they are good models of astrocytes normally found in the brain in vivo ${ }^{14,15}$ and that astrocytes in the brain are functionally coupled to endothelial cells and hence the functions of the blood-brain barrier. ${ }^{16,17}$

Because of the aforementioned considerations, we hypothesized that silicon dioxide nanoparticles induce cytotoxicity in U87 cells by disturbing mitochondrial function and by lowering cell survival via decreasing cell survival signaling. To investigate our hypothesis, we determined the effects of treatment with various concentrations of silicon dioxide nanoparticles on the activities of two key mitochondrial enzymes, ie, citrate synthase and malate dehydrogenase, and expression of the mitochondrial DNAencoded proteins, cytochrome oxidase subunit II and NADH dehydrogenase subunit 6 , and the cell survival signaling pathway protein ERK and phosphorylated ERK in U87 cells.

\section{Materials and methods Materials}

Silicon dioxide nanoparticles (size $12 \mathrm{~nm}$ ) were purchased from STREM Chemicals, Newburyport, MA. Dulbecco's modified Eagle's medium (DMEM) and other chemicals were purchased from Sigma-Aldrich (St. Louis, MO). U87 cells were obtained from American Type Culture Collection (Manassas, VA).

\section{Cell culture}

Human U87 astrocytoma cells were cultured using DMEM supplemented with $10 \%(\mathrm{v} / \mathrm{v})$ fetal bovine serum and antimycotic solution. The cells were maintained in a $75 \mathrm{~cm}^{2}$ flask containing $20 \mathrm{~mL}$ medium, incubated at $37^{\circ} \mathrm{C}$ in a $\mathrm{CO}_{2}$ incubator. When the cells reached $70 \%-80 \%$ confluency, they were harvested either by scrapping or trypsinization and transferred to other flasks.

\section{Preparation of stock suspension of silicon dioxide nanoparticles}

The silicon dioxide nanoparticles stock suspension was first prepared by suspending $50 \mathrm{mg}$ of silicon dioxide nanoparticles in a $100 \mathrm{~mL}$ conical flask containing sterile phosphate-buffered saline. The suspension was then placed 
in a magnetic stirrer to allow the mixture to stir continuously at room temperature before further dilutions were made from the stock (which was being continuously stirred) to be used at specified concentrations and then mixed for use in treating cells.

\section{MTT assay to assess cell viability}

Cells were seeded (2000 cells/well) onto a 96-well plate and allowed to attach to the bottom of each well (inner diameter $0.6 \mathrm{~cm}$ ) for an hour. Silicon dioxide nanoparticles were then added at specified concentrations $(0.1-100 \mu \mathrm{g} / \mathrm{mL})$ to each well containing $0.2 \mathrm{~mL}$ with the cells attached at the bottom and mixed. The plates so prepared were incubated for 48 hours at $37^{\circ} \mathrm{C}$. MTT dye was then added to each well and the plate incubated for another four hours at $37^{\circ} \mathrm{C}$. The purple crystals formed in cells were dissolved using dimethyl sulfoxide and the absorbance of the resultant material in the wells was measured at $567 \mathrm{~nm}$ using the microplate reader as described previously. ${ }^{11}$

\section{Determination of mitochondrial enzyme activity}

The U87 cells were cultured in DMEM in $75 \mathrm{~cm}^{2}$ flasks. When the cells were $70 \%-80 \%$ confluent, silicon dioxide nanoparticle treatments were initiated. The mitochondrial function of the untreated and treated U87 cells was assessed by measuring activities of two tricarboxylic acid cycle enzymes, citrate synthase and malate dehydrogenase, in U87 cells treated with silicon dioxide nanoparticles at 0,25 , 50 , or $100 \mu \mathrm{g} / \mathrm{mL}$ by previously published methods. ${ }^{18}$ The untreated U87 cells served as the control. Citrate synthase and malate dehydrogenase activity in cell homogenates was measured at $412 \mathrm{~nm}$ and $340 \mathrm{~nm}$, respectively, using an ultraviolet-VIS spectrophotometer. ${ }^{18}$

\section{Western blot analysis}

Expression of the mitochondrial DNA-encoded proteins, NADPH dehydrogenase subunit 6 and cytochrome $\mathrm{C}$ oxidase subunit II, and the cell signaling proteins ERK and phosphorylated ERK were determined by Western blot analysis. The U87 cells treated with or without (ie, control) silicon dioxide nanoparticles were collected and homogenized in a buffer containing $5 \mathrm{mM}$ HEPES and $250 \mathrm{mM}$ sucrose, along with protease inhibitors as described previously. ${ }^{15}$ Protein content of the homogenates was then determined using the bicinchoninic acid technique with a microplate reader. ${ }^{11}$ Briefly, equal amounts of protein from the samples were loaded onto the lanes of the gels, and the proteins were separated by polyacrylamide gel electrophoresis and transferred to a polyvinylidene fluoride membrane. ${ }^{19}$ Monoclonal antibodies against the respective proteins were then used to probe the proteins of interest. The polyvinylidene fluoride membrane containing the target protein was then developed using the chemiluminescence technique on an X-ray film to assess the extent of expression of respective proteins. ${ }^{19}$

\section{Assessment of cellular morphology}

The morphology of the U87 cells, treated with silicon dioxide nanoparticles for 48 hours at $37^{\circ} \mathrm{C}$ using specified concentrations, were compared with that of the control or untreated U87 cells by using bright field light microscopy. The images were obtained using a Leica light microscope at $400 \times$ magnification (Leica DM IRB; Leica, Bannockburn, IL) equipped with a digital camera (Leica DFC 300FX; Leica). ${ }^{15}$

\section{Statistical analysis}

Data analysis was performed employing one way ANOVA followed by Dunnett's post hoc test using SPSS software (SPSS Inc., Chicago, IL). All data reported are mean \pm SEM of three individual experiments. Statistical significance was set at $P<0.05$.

\section{Results \\ Effect of nanoparticles on human U87 astrocytoma cell survival}

To determine the effect of silicon dioxide nanoparticles on cell survival, U87 cells were exposed to silicon dioxide nanoparticles for 48 hours at concentrations ranging from 0.1 to $100 \mu \mathrm{g} / \mathrm{mL}$. At lower treatment concentrations, from 0.1 to $10 \mu \mathrm{g} / \mathrm{mL}$, the nanoparticles did not affect viability of the U87 cells (Figure 1). However, at treatment concentrations of $25 \mu \mathrm{g} / \mathrm{mL}$ and higher, silicon dioxide nanoparticles induced concentration-related decreases in survival of U87 cells.

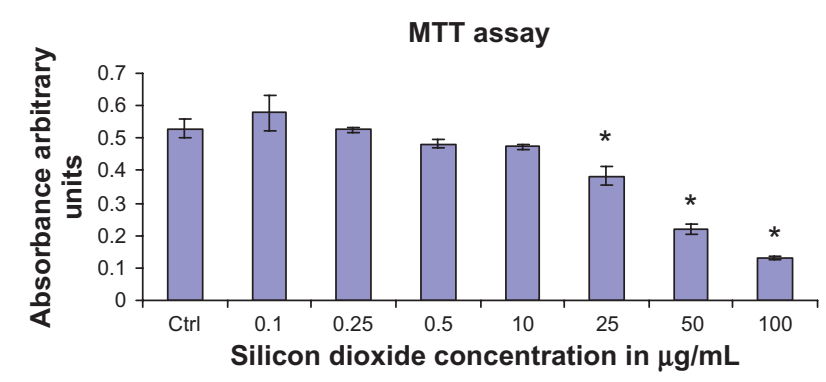

Figure I Effect of treatment with silicon dioxide nanoparticles on survival of human astrocytoma U87 cells. U87 cells were treated at specified concentrations of silicon dioxide nanoparticles for 48 hours. Values were the mean \pm SEM of at least three separate experiments; CTRL represented the untreated (ie, control) U87 cells; $* P<0.05$ versus control cells. 
At the highest treatment level of $100 \mu \mathrm{g} / \mathrm{mL}$, less than $30 \%$ of the cells survived (Figure 1).

\section{Effect on mitochondrial function in human U87 astrocytoma cells}

Because cell survival critically depends on mitochondrial functions being maintained at a normal physiologic level, we determined the effect of silicon dioxide nanoparticles on mitochondrial function in U87 cells by monitoring the activities of citrate synthase and malate dehydrogenase. ${ }^{18}$ Both enzymes are nuclear DNA-encoded; these enzyme proteins are synthesized in the endoplasmic reticulum and then imported into the mitochondrial matrix compartment.

At treatment concentrations of $25-100 \mu \mathrm{g} / \mathrm{mL}$ for 48 hours, silicon dioxide nanoparticles induced dose-related increases in citrate synthase activities in U87 cells (Figure 2). On the other hand, although at the same concentrations the nanoparticles also induced significantly increased activity in malate dehydrogenase in U87 cells, the increases were not dose-related (Figure 3). Using the same nanoparticle concentrations for treatment of U87 cells, there was a doserelated decrease in cell survival (Figure 1), and it is likely that the remaining surviving U87 cells were compensating by upregulation of citrate synthase and, to a less extent, malate dehydrogenase, so as to maintain their energy production via tricarboxylic acid cycle metabolism for survival.

\section{Effects of nanoparticles on mitochondrial DNA-encoded and cell signaling protein expression}

Because silicon dioxide nanoparticles induced dose-related decreases in survival of U87 cells at concentrations of

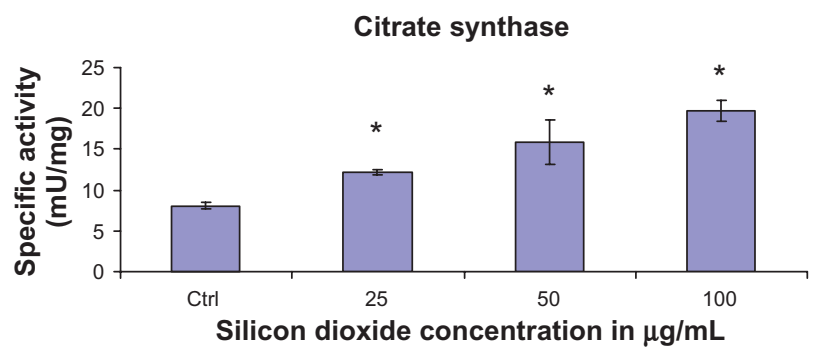

Figure 2 Effect of treatment with silicon dioxide nanoparticles on specific activities of citrate synthase in human astrocytoma U87 cells. U87 cells were treated at specified concentrations of silicon dioxide nanoparticles for 48 hours. Then the activities of citrate synthase in the homogenates of treated and untreated (ie, control, ctrl) U87 cells were determined as described in Materials and methods; the activities of citrate synthase were expressed per $\mathrm{mg}$ of homogenate protein as specific activities. The specific activities values were the mean \pm SEM of at least three separate experiments; ctrl represented the value in untreated U87 cell homogenate; $* P<0.05$ versus that of control cells.

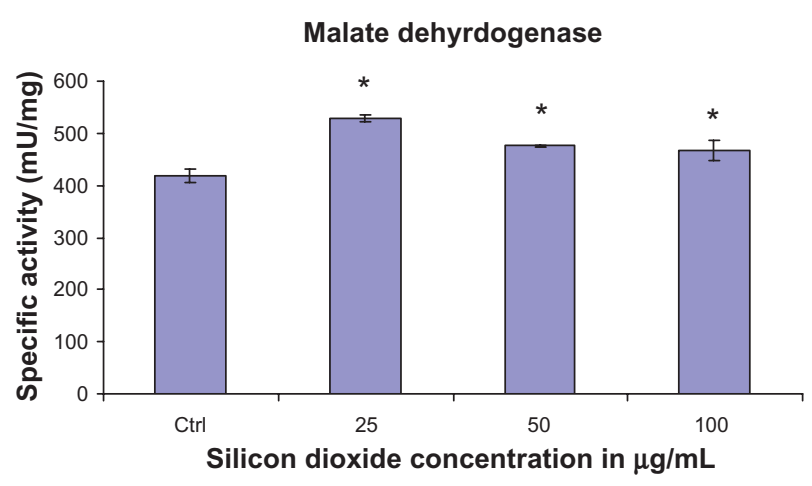

Figure 3 Effect of treatment with silicon dioxide nanoparticles on specific activities of malate dehydrogenase in human astrocytoma U87 cells. U87 cells were treated at specified concentrations of silicon dioxide nanoparticles for 48 hours. Then the activities of malate dehydrogenase in the homogenates of treated and untreated (ie, control, ctrl) U87 cells were determined as described in Materials and methods; the activities of malate dehydrogenase were expressed per $\mathrm{mg}$ of homogenate protein as specific activities. The specific activity values were the mean \pm SEM of at least three separate experiments; ctrl represented the value in untreated $U 87$ cell homogenate; $* p<0.05$ versus that of control cells.

25-100 $\mu \mathrm{g} / \mathrm{mL}$ over 48 hours (Figure 1), we investigated the possibility that these decreases in survival can be attributed to the nanoparticle-induced alterations in expression of mitochondrial DNA-encoded and cell signaling proteins (Figures 4-6).

At treatment concentrations of $25-100 \mu \mathrm{g} / \mathrm{mL}$ for 48 hours, silicon dioxide nanoparticles induced dose-related decreases in the expression of cytochrome $\mathrm{C}$ oxidase subunit II and NADH dehydrogenase subunit 6 (two mitochondrial DNA-encoded peptides) in U87 cells (Figures 4 and 5). These results strongly suggested treatment with silicon dioxide nanoparticles altered the normal functioning of the mitochondrial genome in U87 cells. A likely consequence

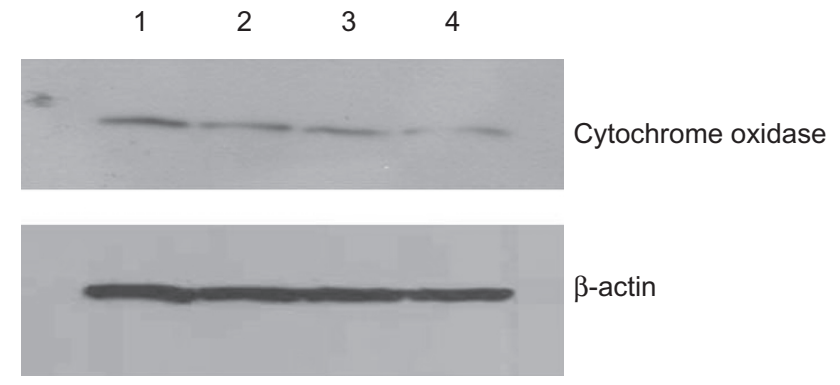

Figure 4 Effect of treatment with silicon dioxide nanoparticles on expression of cytochrome oxidase subunit II in human astrocytoma U87 cells. U87 cells were treated at specified concentrations of silicon dioxide nanoparticles for 48 hours. Then cell lysates of treated and untreated (ie, control) U87 cells were prepared as described in Materials and methods. The expression of cytochrome oxidase subunit II, encoded by mitochondrial DNA, was determined by Western blot analysis using $\beta$-actin as the loading control: Lane I, lysate of untreated or control U87 cells; lane 2, lysate of U87 cells treated with silicon dioxide nanoparticles at $25 \mu \mathrm{g} / \mathrm{mL}$; lane 3, lysate of U87 cells treated with silicon dioxide nanoparticles at $50 \mu \mathrm{g} / \mathrm{mL}$; lane 4 , lysate of U87 cells treated with silicon dioxide nanoparticles at $100 \mu \mathrm{g} / \mathrm{mL}$. The blots were from a typical experiment. Two other experiments yielded essentially the same trend of results. 
1

2

3

4

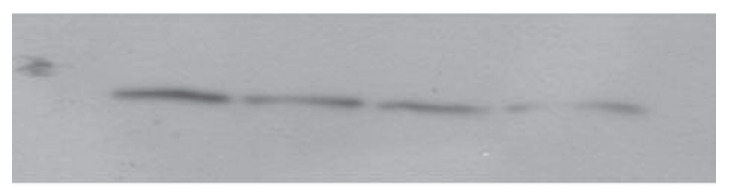

ND-6

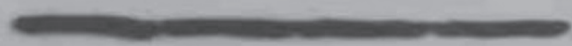

$\beta$-actin

Figure 5 Effect of treatment with silicon dioxide nanoparticles on expression of nicotinamide adenine dinucleotide (NADH) dehydrogenase subunit 6 in human astrocytoma U87 cells. U87 cells were treated at specified concentrations of silicon dioxide nanoparticles for 48 hours. Then cell lysates of treated and untreated (ie, control) U87 cells were prepared as described in Materials and methods. The expression of NADH dehydrogenase subunit 6, encoded by mitochondrial DNA, was determined by Western blot analysis using $\beta$-actin as the loading control: Lane I, lysate of untreated or control U87 cells; lane 2, lysate of U87 cells treated with silicon dioxide nanoparticles at $25 \mu \mathrm{g} / \mathrm{mL}$; lane 3 , lysate of $U 87$ cells treated with silicon dioxide nanoparticles at $50 \mu \mathrm{g} / \mathrm{mL}$; lane 4 , lysate of $U 87$ cells treated with silicon dioxide nanoparticles at $100 \mu \mathrm{g} / \mathrm{mL}$. The blots were from a typical experiment. Two other experiments yielded essentially the same trend of results.

of this effect is impairment in the mitochondrial electron transport chain in U87 cells. Indeed, the nanoparticle-induced disruption of mitochondrial respiratory chain structure and function may be one cause of energy failure that ultimately led to the death of U87 cells.

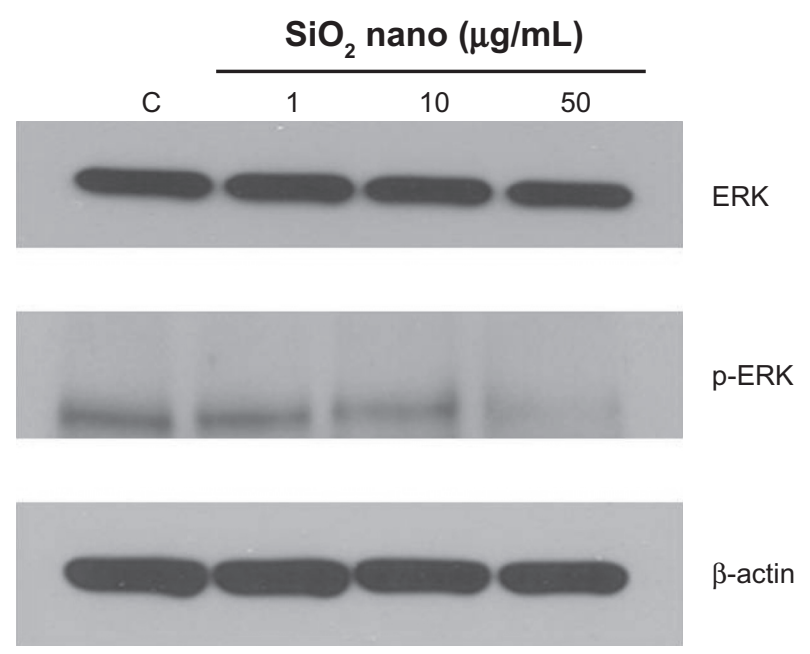

Figure 6 Effect of treatment with silicon dioxide nanoparticles on expression of extracellular signal regulated kinase (ERK) and phosphorylated ERK (p-ERK) in human astrocytoma U87 cells. U87 cells were treated at specified concentrations of silicon dioxide nanoparticles for 48 hours. Then cell lysates of treated and untreated (ie, control) U87 cells were prepared as described in Materials and methods. The expression of ERK and phosphorylated ERK was determined by Western blot analysis using $\beta$-actin as the loading control: Lane marked $C$, lysate of untreated or control U87 cells; lane marked I, lysate of U87 cells treated with silicon dioxide nanoparticles at I $\mu \mathrm{g} / \mathrm{mL}$; lane marked 10, lysate of U87 cells treated with silicon dioxide nanoparticles at $10 \mu \mathrm{g} / \mathrm{mL}$; lane marked 50 , lysate of U87 cells treated with silicon dioxide nanoparticles at $50 \mu \mathrm{g} / \mathrm{mL}$. The blots were from a typical experiment. Two other experiments yielded essentially the same trend of results.
Other than their effect of depressing the mitochondrial respiratory chain, thereby decreasing oxidative phosphorylation, treatment of U87 cells with silicon dioxide nanoparticles could also lower survival of U87 cells through altering cell signaling pathway(s) that regulate(s) cell survival and proliferation. ${ }^{20}$ We therefore investigated this possibility by examining the effect of these nanoparticles on expression of ERK and phosphorylated ERK proteins. We observed that when U87 cells were treated with silicon dioxide nanoparticles $1-50 \mu \mathrm{g} / \mathrm{mL}$ for 48 hours, the protein expression of phosphorylated ERK showed a dose-related decrease, while that of ERK protein remained essentially unchanged (Figure 6), suggesting that a lowering of this cell survival/proliferation signaling mechanism could, at least in part, account for the dose-related decrease in U87 cell survival induced by these nanoparticles.

\section{Effect on morphology of U87 cells}

To ascertain whether or not treatment of U87 cells with silicon dioxide nanoparticles led to any gross changes in their morphology, we examined the cells under bright field light microscopy (Figure 7). We observed that as we exposed U87 cells to increasing concentrations of silicon dioxide nanoparticles higher than $25 \mu \mathrm{g} / \mathrm{mL}$, the cells became more and more enlarged and swollen, suggesting that they assumed a pathologic appearance (Figure 7).

\section{Discussion}

Few, if any, recent studies have addressed the cytotoxic effects of silicon dioxide nanoparticles in neural cells. As far as we are aware, ours is the first to report the cytotoxic effects of silicon dioxide nanoparticles on human astrocytoma U87 cells and some of the underlying subcellular mechanisms. Consistent with our hypothesis that silicon dioxide nanoparticles induce cytotoxicity in U87 cells by disturbing mitochondrial function and by lowering cell survival via decreasing cell survival signaling, we found that treatment with silicon dioxide nanoparticles induced concentration-related lowering of protein expression of the mitochondrial DNA-encoded cytochrome C oxidase subunit II and NADH dehydrogenase subunit 6, two key components of the mitochondrial respiratory chain, and phosphorylated ERK, a key cell survival/proliferation signaling molecule in U87 cells. It is noteworthy that we found those changes in protein expression at concentrations of silicon dioxide nanoparticles that correlated with those inducing concentration-related decreases in survival of U87 cells. 


\section{Control}

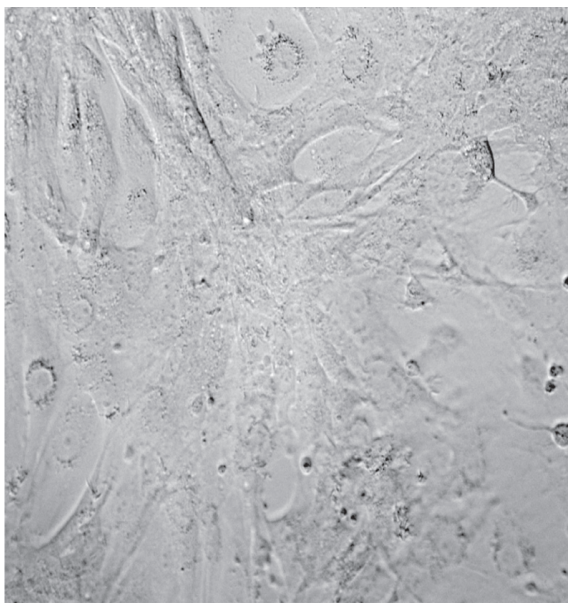

$\mathrm{SiO}_{2} 50 \mu \mathrm{g} / \mathrm{mL}$

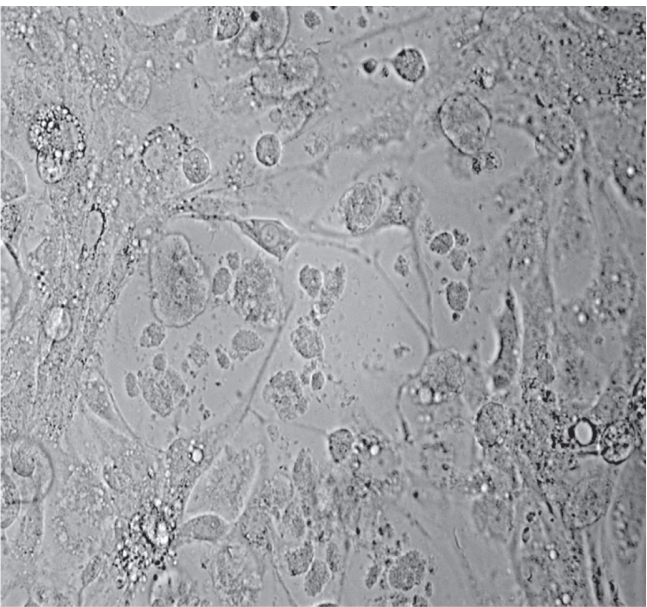

$\mathrm{SiO}_{2} 25 \mu \mathrm{g} / \mathrm{mL}$

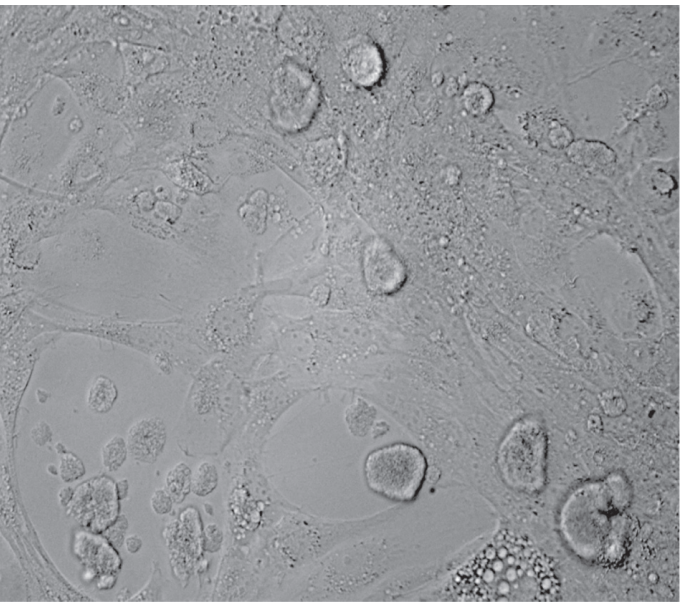

$\mathrm{SiO}_{2} 100 \mu \mathrm{g} / \mathrm{mL}$

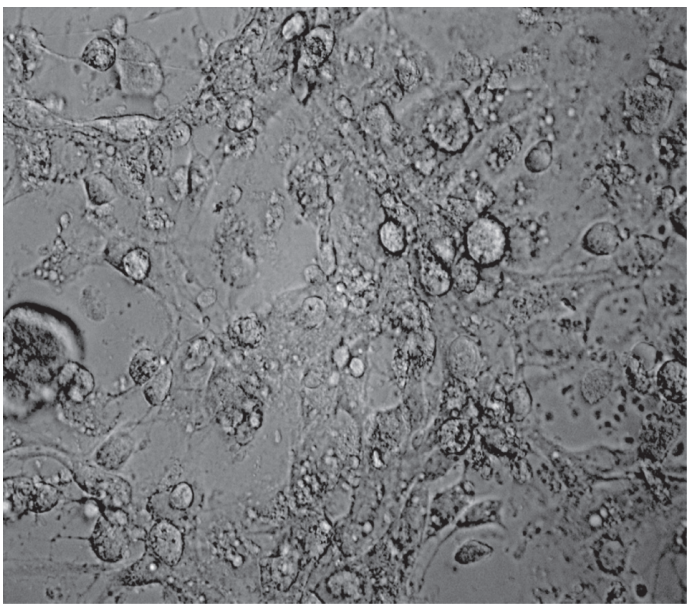

Figure 7 Effect of treatment with silicon dioxide nanoparticles on the morphology of human astrocytoma U87 cells. U87 cells were treated at specified concentrations of silicon dioxide nanoparticles for 48 hours. Then the morphology of treated and untreated (ie, control) U87 cells were assessed using bright field light microscopy at $400 \times$ magnification as described in Materials and methods. The photomicrographs shown were representative of those obtained in several studies.

As emphasized earlier, the initial rationale for focusing our studies on $\mathrm{U} 87$ cells was that few studies have addressed the putative cytotoxic effects of silicon dioxide nanoparticles on neural cells, especially those from the human brain. More importantly, not only do astrocytes have many physiologic roles (eg, metabolic trafficking, neurotransmitter cycling, protecting neurons from pathophysiologic assaults), ${ }^{15,21,22}$ they also play pathophysiologic roles in disease states (eg, neuroinflammation in neurodegenerative diseases such as Alzheimer's disease and Parkinson's disease). ${ }^{22}$ Furthermore, it is relevant to note that although U87 are neurotumor cells, they possess many of the "normal" physiologic characteristics of astrocytes detected in primary cultures of astrocytes and astrocytes in the brain in vivo. ${ }^{14,15}$ Thus, U87 cells constitute a good model system in vitro for brain astrocytes. ${ }^{14,15}$ Consequently, we have employed U87 cells as a model system to elucidate the putative cytotoxicity of nanoparticles on neural cells in a systematic manner. ${ }^{11}$

One neurotoxic effect of a neurotoxicant, such as manganese, is via a lowering of cell survival/proliferation signaling molecule expression, leading ultimately to death of neural cells. ${ }^{20}$ Consistent with this observation is our finding in this study that treatment of U87 cells with increasing concentrations of silicon dioxide nanoparticles induced a dose-related decrease in protein expression of phosphorylated ERK (Figure 6), one important cell survival/ proliferation signaling molecule. ${ }^{20}$ This effect correlated quite well with the dose-related decrease in survival of these cells (Figure 1) and alterations in their morphology (Figure 7) induced by the nanoparticles. Moreover, we also found that in U87 cells treated in the same nanoparticle dose 
range, there was a concentration-related decrease in protein expression of mitochondrial DNA-encoded cytochrome C oxidase subunit II and NADH dehydrogenase subunit 6 (Figures 4 and 5).

Our present findings that exposure of human astrocytoma U87 cells to silicon dioxide induced dose-related decreases in cell survival and alteration of their mitochondrial structure and function (Figures 1-6) are similar to those of Chen et $\mathrm{al}^{23}$ who demonstrated that exposure of human brain microvascular endothelial cells to aluminum oxide nanoparticles induced decreased viability of those cells, alteration in their mitochondrial membrane potential, and a lowering of their tight junction protein expression. Consequently, in this context, our finding that silicon dioxide nanoparticles induced a dose-related lowering of the expression of cytochrome $\mathrm{C}$ oxidase subunit II and NADH dehydrogenase subunit 6 is of pathophysiologic importance and interest in several respects. Because these two peptides are structural components of the mitochondrial respiratory chain complexes IV and I, respectively, and have key functional roles in that respiratory chain, ${ }^{24}$ decreased expression of these peptides induced by the nanoparticles likely results in dysfunction in the mitochondrial respiratory chain and oxidative phosphorylation, leading ultimately to decreased adenosine triphosphate synthesis. Consequently, the decreased expression of the two mitochondrial DNA-encoded peptides could likely contribute to decreasing U87 cell survival induced by silicon dioxide nanoparticles through necrotic cell death as a result of energy failure. ${ }^{11}$ This conclusion is certainly consistent with our observation that the U87 cells assumed an increasingly swollen appearance, a hallmark of necrosis, as we increased their treatment levels of silicon dioxide nanoparticles (Figure 7). The decreased expression of cytochrome $\mathrm{C}$ oxidase subunit II and NADH dehydrogenase subunit 6 peptides induced by the nanoparticles could reflect the effect of the nanoparticles on altering communication between the mitochondrial genome and the nuclear genome, decreasing mitochondrial peptide synthesis, disruption of protein targeting to mitochondria, and/or a combination of these mechanisms. The nanoparticle-induced decrease in protein expression of the two peptides could also result from the overall effect of the nanoparticles on survival/ proliferation signaling in U87 cells. Clearly, these are novel but mechanistically relevant possibilities that deserve further investigation.

Unlike the downregulation of the protein expression of mitochondrial DNA-encoded cytochrome C oxidase subunit II and NADH dehydrogenase subunit 6, and the survival/proliferation signaling molecule phosphorylated ERK, treatment of U87 cells with silicon dioxide nanoparticles induced concentration-related increases in the activity of citrate synthase and malate dehydrogenase, both of which are located in the mitochondrial matrix (Figures 2 and 3). Because the increases in citrate synthase and malate dehydrogenase activity were observed at nanoparticle concentrations that also induced dose-related decreases in U87 cell survival (Figure 1), one possible, and likely, explanation for the increased citrate synthase and malate dehydrogenase activity is that the surviving cells were showing compensatory/adaptive mechanisms involving upregulation of tricarboxylic acid cycle enzymes in the mitochondrial matrix of surviving or dying cells, or both, in the face of downregulation of mitochondrial DNA-encoded respiratory chain components, such as cytochrome $\mathrm{C}$ oxidase subunit II and NADH dehydrogenase subunit 6 . Consequently, this upregulation of tricarboxylic acid cycle enzymes may offset (or compensate for) the effect on mitochondrial energetics through the downregulation of respiratory chain components induced by the nanoparticles. Only future studies can elucidate whether this mechanistic possibility is tenable because they are beyond the scope of the present study.

Because ours is the first study to report on the cytotoxic effects of silicon dioxide nanoparticles on human neural cells, only a few comparisons can be made with the effects of silicon dioxide nanoparticles on neural and peripheral cell types because the literature in this area of research is rather scant. ${ }^{11}$ For example, Napierska et $\mathrm{al}^{7}$ demonstrated exposure of human endothelial cells to amorphous spherical silicon dioxide nanoparticles induced decreases in their viability and this effect was apparently dependent on their particle size. Several groups had also shown that silicon dioxide nanoparticles decreased viability of some peripheral human and other mammalian cell types..$^{5,25,26}$ Thus, recent reports, ${ }^{5,7,25,26}$ as well as the findings of this study, are in accord in emphasizing that silicon dioxide nanoparticles induces decreased viability of a variety of human and other mammalian cell types. Nevertheless, more systematic studies are required to elucidate fully the molecular mechanisms underlying the cytotoxicity of these nanoparticles.

As we discussed previously, one early study indicated that when silicon nanoparticles were introduced directly into the brains of rats and mice, they induced an inflammatory response in brain astrocytes. ${ }^{8}$ Furthermore, silicon was found in senile plaque cores and in lipofuscin granules in the cortex of patients who died of Alzheimer's disease. ${ }^{9,10}$ 
In view of these earlier findings, ${ }^{8-10}$ because astrocytes play important roles in neuroinflammation, ${ }^{22}$ and U87 cells constitute a good cell model for astrocytes, the results of this study may have pathophysiologic implications in the inflammation in astrocytes in Alzheimer's disease in particular and in neuroinflammation in general. Thus, the mechanistic connection between the inflammatory response in Alzheimer's disease, neuroinflammation, and the cytotoxic effects of silicon dioxide nanoparticles in neural cells merits further investigation.

\section{Conclusion}

This study is the first to report on the cytotoxic effects of silicon dioxide nanoparticles on human astrocytoma U87 cells, and some of the underlying subcellular mechanisms. Consistent with our hypothesis, we found that treatment with silicon dioxide nanoparticles induced concentration-related lowering of protein expression in the mitochondrial DNA-encoded cytochrome $\mathrm{C}$ oxidase subunit II and NADH dehydrogenase subunit 6, two key components of the mitochondrial respiratory chain, and phosphorylated ERK, a key cell survival/proliferation signaling molecule in U87 cells. We also noted those changes in protein expression induced by silicon dioxide nanoparticles correlated with concentration-related decreases in survival of U87 cells induced by the nanoparticles. On the other hand, we observed upregulation of citrate synthase and malate dehydrogenase, two key tricarboxylic acid cycle enzymes. Those changes were likely compensatory/ adaptive mechanism of dying and/or surviving U87 cells. Thus, our findings may assume pathophysiologic importance in neuroinflammation and Alzheimer's disease and in the environmental health impact of human exposure to these nanoparticles. This is obviously a worthwhile area for further study.

\section{Acknowledgments}

Our studies were supported by a US Army Medical Research and Material Command Project Grant (Contract W81XWH-07-2-0078) and National Institutes of Health Grant P20 RR016454 from the Idaho IdeA Biomedical Research Excellence Program of the National Center for Research Resources. JCKL and GA contributed equally to this work.

\section{Disclosure}

The authors report no conflicts of interest in this work.

\section{References}

1. Environmental Protection Agency. Draft Nanomaterial Research Strategy. Available at: (http://epa.gov/ncer/nano/publications/nano_ strategy_012408.pdf). Accessed August 3, 2010.

2. Martin KR. The chemistry of silica and its potential health benefits. J Nutr Health Aging. 2007;11:94-97.

3. Jonat S, Hasenzahl S, Gray A, Schmidt PC. Influence of compacted hydrophobic and hydrophilic colloidal silicon dioxide on tableting properties of pharmaceutical excipients. Drug Dev Ind Pharm. 2005; 31:687-696.

4. Ulrichs C, Krause F, Rocksch T, et al. Electrostatic applications of inert silica dust based insecticides onto plant surfaces. Commun Agric Appl Biol Sci. 2006;71:171-178.

5. Sayes CM, Reed KL, Warheit DB. Assessing toxicity of fine and nanoparticles: Comparing in vitro measurements to in vivo pulmonary toxicity profiles. Toxicol Sci. 2007;97:163-180.

6. Adams LK, Lyon DY, McIntosh A, Alvarez PJ. Comparative toxicity of nano-scale $\mathrm{TiO}_{2}, \mathrm{SiO}_{2}$, and $\mathrm{ZnO}$ water suspensions. Water Sci Technol. 2006;54:327-334.

7. Napierska D, Thomassen LC, Rabolli V, et al. Size-dependent cytotoxicity of monodisperse silica nanoparticles in human endothelial cells. Small. 2009;5:846-853.

8. Rees S, Cragg B. Is silica involved in neuritic (senile) plaque formation? Acta Neuropathol. 1983;59:31-40.

9. Candy JM, Oakley AE, Klinowski J, et al. Aluminosilicates and senile plaque formation in Alzheimer's disease. Lancet. 1986;1: 354-357.

10. Takutake S, Oyanagi S. Accumulation of aluminium and silicon in lipofuscin granules. Gerontology. 1995;41 Suppl 2:131-144.

11. Lai JC, Lai MB, Jandhyam S, et al. Exposure to titanium dioxide and other metallic oxide nanoparticles induces cytotoxicity on human neural cells and fibroblasts. Int J Nanomedicine. 2008;3:533-545.

12. Kim JS, Yoon T-J, Yu KN, et al. Toxicity and tissue distribution of magnetic nanoparticles in mice. Toxicol Sci. 2006;89:338-347.

13. Sharma HS, Hussain S, Schlager J, et al. Influence of nanoparticles on blood-brain barrier permeability and brain edema formation in rats. Acta Neurochir Suppl. 2010;106:359-364.

14. Malthankar GV, White BK, Bhushan A, et al. Differential lowering by manganese treatment of activities of glycolytic and tricarboxylic acid (TCA) cycle enzymes investigated in neuroblastoma and astrocytoma cells is associated with manganese-induced cell death. Neurochem Res. 2004;29:709-717.

15. Dukhande VV, Malthankar-Phatak GH, Hugus JJ, et al. Manganese induced neurotoxicity is differentially enhanced by glutathione depletion in astrocytoma and neuroblastoma cells. Neurochem Res. 2006;31:1349-1357.

16. Haseloff RE, Blasig IE, Bauer H-C, Bauer H. In search of the astrocytic factor(s) modulating blood-brain barrier functions in brain capillary endothelial cells in vitro. Cell Mol Neurobiol. 2005;25: 25-39.

17. Liebner S, Plate KH. Differentiation of the brain vasculature: The answer came blowing by the Wnt. J Angiogenes Res. 2010:2:1-10.

18. Clark JB, Lai JCK. Glycolytic, tricarboxylic acid cycle, and related enzymes in brain. In: Boulton AA, Baker GB, Butterworth RF (editors). NeuroMethods Vol 11. Clifton, NJ: Humana Press; 1989:233-281.

19. Isaac AO, Dukhande VV, Lai JCK. Metabolic and antioxidant system alterations in an astrocytoma cell line challenged with mitochondrial DNA deletion. Neurochem Res. 2007;32:1906-1918.

20. Puli S, Lai JCK, Edgley KL, et al. Signaling pathways mediating manganese-induced neurotoxicity in human glioblastoma cells (U87). Neurochem Res. 2006;31:1211-1218.

21. Faharani R, Pina-Benabou MH, Kyrozis A, et al. Alterations in metabolism and gap junction protein expression may determine the role of astrocytes as "Good Samaritans" or executioners. Glia. 2005;50: $351-361$. 
22. Sofroniew MV, Vinters HV. Astrocytes: Biology and pathology. Acta Neuropathol. 2010;119:7-35.

23. Chen L, Yokel RA, Hennig B, Toborek M. Manufactured aluminum oxide nanoparticles decrease expression of tight junction proteins in brain vasculature. J Neuroimmune Pharmacol. 2008;3:286-295.

24. Heales SJR, Gegg ME, Clark JB. Oxidative phosphorylation: Structure, function, and intermediary metabolism. Int Rev Neurobiol. 2002; $53: 25-56$.
25. Lin W, Huang YW, Zhou XD, Ma Y. In vitro toxicity of silica nanoparticles in human lung cancer cells. Toxicol Appl Pharmacol. 2006;217:252-259.

26. Adili A, Crowe S, Beaux II FM, et al. Differential cytotoxicity exhibited by silica nanowires and nanoparticles. Nanotoxicology. 2008;2:1-8.

International Journal of Nanomedicine

\section{Publish your work in this journal}

The International Journal of Nanomedicine is an international, peerreviewed journal focusing on the application of nanotechnology in diagnostics, therapeutics, and drug delivery systems throughout the biomedical field. This journal is indexed on PubMed Central, MedLine, CAS, SciSearch ${ }^{\circledR}$, Current Contents ${ }^{\circledR} /$ Clinical Medicine,

\section{Dovepress}

Journal Citation Reports/Science Edition, EMBase, Scopus and the Elsevier Bibliographic databases. The manuscript management system is completely online and includes a very quick and fair peer-review system, which is all easy to use. Visit http://www.dovepress.com/ testimonials.php to read real quotes from published authors.

Submit your manuscript here: http://www.dovepress.com/international-journal-of-nanomedicine-journal 